Check for updates

Cite this: RSC Adv., 2017, 7, 29122

\title{
Visual detection of glucose using triangular silver nanoplates and gold nanoparticles $\dagger$
}

\author{
Tuanjie Cai, Yan Gao, Jilin Yan, Ying Wu and Junwei Di (D)* \\ A sensitive spectrophotometric detection of glucose based on triangular silver nanoplates (Ag TNPs) \\ coupled with gold nanoparticles (Au NPs) was carried out. Relying on the glucose oxidase (GOD) \\ mimetics of small Au NPs, glucose was catalytically oxidized in the presence of oxygen. The product of \\ $\mathrm{H}_{2} \mathrm{O}_{2}$ then induced the etching of Ag TNPs from triangular to round, which led to blue-shifting of the \\ peak wavelength and a decrease of the absorbance. The color changes of the solution could be used for \\ visual detection (from dark blue to light pink) of glucose by the naked eye. The blue-shift of the peak \\ wavelength was linear proportional to the glucose concentration in the range from 0.5 to $20 \mu \mathrm{M}$ with \\ a detection limit of $0.3 \mu \mathrm{M}$. The high sensitivity of the method is due to the highly reactive tips and \\ strong tip sharpness of Ag TNPs. Moreover, the effect of L-cysteine (Cys) assembled on metal \\ nanomaterials was investigated in the system.
}

Received 14th January 2017

Accepted 24th May 2017

DOI: $10.1039 / \mathrm{c} 7 \mathrm{ra00593h}$

rsc.li/rsc-advances

limitations such as instability for the denaturation in harsh conditions, the difficulties in the procedures for preparation, purification, and storage. ${ }^{19}$

In recent years, noble metal (especially $\mathrm{Au}$ and $\mathrm{Ag}$ ) nanoparticles have attracted intensive attention in colorimetric detection of glucose. It was demonstrated that the small $\mathrm{Au}$ nanoparticles (Au NPs) exhibit a dramatic high activity in the aerobic oxidation of glucose. ${ }^{20,21}$ Zeng et al. coupled horseradish peroxidase (HRP) with GOD-like Au NPs to simulate the function of the GOD-HRP enzyme pair for colorimetric detection of glucose with organic chromogenic agent. ${ }^{22}$ On the other hand, the localized surface plasmon resonance (LSPR) band of noble metal nanoparticles is extremely dependent on their size, shape, composition, and the surrounding media. ${ }^{23,24} \mathrm{Ag}$ nanoparticles (Ag NPs) can be etched by $\mathrm{H}_{2} \mathrm{O}_{2},{ }^{25}$ resulting in the change of its LSPR band. Glucose could be detected by coupling $\mathrm{Ag}^{8,26,27}$ or $\mathrm{Ag} / \mathrm{Au}^{28}$ nanoparticles with GOD to assemble a catalytical nanoconjugate. By combination of the good catalytic performances and the excellent optical properties of the two metal nanomaterials, an Au NPs-Ag NPs sensor was developed for colorimetric detection of glucose in our previous report. ${ }^{29}$ Furthermore, triangular silver nanoplates (Ag TNPs) could be etched from triangle to round by $\mathrm{H}_{2} \mathrm{O}_{2}$ to cause a blue-shift of their LSPR. $^{30,31}$ In this work, we coupled triangular silver nanoplates (Ag TNPs) with small Au NPs to develop a plasmonic sensing for glucose. The Ag TNPs have advantages of highly reactive tips and strongly tip sharpness, resulting in large blueshift of the LSPR due to etching of the angles first. The blueshift of peak wavelength and the decrease of peak intensity could be used to sensitive detection of glucose. Moreover, we compared the effect of various stabilizers of metal nanoparticles College of Chemistry, Chemical Engineering and Material Science, Soochow University, Suzhou, 215123, PR China.E-mail: djw@suda.edu.cn

$\dagger$ Electronic supplementary information (ESI) available. See DOI: in the catalytic reaction and selectivity. 


\section{Experimental section}

\subsection{Chemicals and reagents}

Silver nitrates $\left(\mathrm{AgNO}_{3}\right)$ was purchased from Shanghai Reagent Factory (China). Chloroauric acid $\left(\mathrm{HAuCl}_{4} \cdot 4 \mathrm{H}_{2} \mathrm{O}\right)$, sodium citrate $\left(\mathrm{Na}_{3} \mathrm{C}_{6} \mathrm{H}_{5} \mathrm{O}_{7} \cdot 2 \mathrm{H}_{2} \mathrm{O}\right)$, citric acid $\left(\mathrm{C}_{6} \mathrm{H}_{8} \mathrm{O}_{7}\right)$, disodium hydrogen phosphate $\left(\mathrm{Na}_{2} \mathrm{HPO}_{4}\right)$, sodium borohydride $\left(\mathrm{NaBH}_{4}\right)$, hydrogen peroxide $\left(\mathrm{H}_{2} \mathrm{O}_{2}\right)$, glucose, fructose, L-cysteine (Cys), ascorbic acid (AA), uric acid (DA), paracetamol (PA), polyvinyl pyrrolidone (PVP), bovine serum albumin (BSA), and glycine, were acquired from Sinopharm Chemical Reagent Co., Ltd (China). All chemicals were of analytical grade. All aqueous solutions were prepared using ultrapure water $(18.2 \mathrm{M} \Omega \mathrm{cm})$ obtained by a Milli-Q system.

\subsection{Instruments and characterization}

An Agilent Cary-60 spectrophotometer was used to record the UV-vis absorption spectra. TEM images and element mapping images were taken using a TecnaiG20 (FEI, U.S.A) transmission electron microscope operated at $185 \mathrm{kV}$. All TEM samples were prepared by dispersing $6 \mu \mathrm{L}$ of the stable mixed solution on the surface of the copper mesh.

\subsection{Preparation of Ag TNPs}

The Ag TNPs were synthesized according to the standard procedures with slight modifications. ${ }^{32}$ Typically, a solution containing $50 \mathrm{~mL}$ of $0.1 \mathrm{mM}$ silver nitrate, $3 \mathrm{~mL}$ of $30 \mathrm{mM}$ trisodium citrate and $3 \mathrm{~mL}$ of $0.02 \mathrm{~g} \mathrm{~mL}^{-1}$ PVP were vigorously stirred at room temperature, then $0.5 \mathrm{~mL}$ of $40 \mathrm{mM}$ sodium borohydride was injected into this mixture, immediately leading to a light-yellow solution. Next, $0.2 \mathrm{~mL}$ of $30 \% \mathrm{H}_{2} \mathrm{O}_{2}$ was rapidly added to the solution, which turned to colorless. After continuous stirring 3 minutes, the reaction was carried out in darkness for one hour. Finally, the prepared solution was added $50 \mu \mathrm{M}$ of Cys. The blue Ag TNPs solution was stored at $4{ }^{\circ} \mathrm{C}$ before use.

\subsection{Preparation of Au NPs}

The Au NPs were synthesized according to the standard $\mathrm{NaBH}_{4}$ reduction procedures with slight modifications. Briefly, $0.5 \mathrm{~mL}$ of $10 \mathrm{mM} \mathrm{HAuCl}_{4}$ and $0.5 \mathrm{~mL}$ of $10 \mathrm{mM}$ sodium citrate solution were mixed and diluted to $20 \mathrm{~mL}$ with water. Then a $0.5 \mathrm{~mL}$ of freshly prepared $100 \mathrm{mM} \mathrm{NaBH}_{4}$ solution was added into the solution under stirring at room temperature. The solution color changed immediately from colorless to orange. Approximately one hour later, $0.1 \mathrm{~mL}$ of $10 \mathrm{mM}$ Cys was added into the solution to decorate $\mathrm{Au}$ NPs. The resulted $\mathrm{Au}$ NP solution was stored at $4{ }^{\circ} \mathrm{C}$.

\subsection{Procedures for glucose sensing}

To a series of $5 \mathrm{~mL}$ test tubes, $100 \mu \mathrm{L}$ of Au NPs solution and 100 $\mu \mathrm{L}$ of $0.05 \mathrm{M}$ trisodium citrate-citric acid buffer solution $(\mathrm{pH}=$ 6.6) was diluted with $700 \mu \mathrm{L}$ water saturated with oxygen. The mixed solution was warmed to $35^{\circ} \mathrm{C}$. Then, $100 \mu \mathrm{L}$ of glucose stand solution or diluted human serum samples were added in the mixed solution for 30 minutes at $35{ }^{\circ} \mathrm{C}$. Next, $1 \mathrm{~mL}$ of $\mathrm{Ag}$ TNPs solution was added in the mixture and incubated at $35^{\circ} \mathrm{C}$ for 30 minutes in the dark. The UV-vis absorption spectra were recorded at the room temperature.

\section{Results and discussion}

\subsection{Characterization of Au NPs and Ag TNPs}

The formation and properties of the Au NPs and Ag TNPs were characterized by UV-vis absorption spectra and TEM images. The Au NPs were fabricated by reducing $\mathrm{HAuCl}_{4}$ with $\mathrm{NaBH}_{4}$, producing an average diameter of $\sim 4.5 \mathrm{~nm}$ nanoparticles with a peak at $\sim 509 \mathrm{~nm}$ in UV-vis absorption spectrum (Fig. S1 $\dagger$ ). The Ag TNPs were prepared by reducing $\mathrm{AgNO}_{3}$ with $\mathrm{NaBH}_{4}$ and then treatment with $\mathrm{H}_{2} \mathrm{O}_{2}$. The UV-vis absorption spectrum (Fig. S2A $\dagger$ ) showed three peaks of $\sim 633,450$, and $335 \mathrm{~nm}$, corresponding to in-planedipole, in-plane quadrupole, and outof-plane quadrupole resonance, respectively. ${ }^{33}$ The side length of the Ag TNPs was $\sim 40 \mathrm{~nm}$ (Fig. S2B $\dagger$ ) and their thickness was only $\sim 4 \mathrm{~nm}$ (Fig. S2Cं), which leading to highly sharp edges/ tips.

Fig. 1A shows the UV-vis absorption of the Ag TNPs solution mixed with different volumes of Au NPs. It was found that the main absorption peak of Ag TNPs at $\sim 633 \mathrm{~nm}$ was slightly redshifted in wavelength and decreased in intensity after sequent addition of Au NPs. In order to get further information, TEM images and EDX patterns of mixture of $\mathrm{Au}$ NPs-Ag TNPs were investigated. Fig. 1B exhibits that the morphology of Au NPs and Ag TNPs was no marked changes, compared with that of individual $\mathrm{Au}$ NPs and $\mathrm{Ag}$ TNPs (Fig. S1B and S2B $\dagger$ ). The EDX elemental mapping images of Au NPs-Ag TNPs (Fig. 1C-E) show a little of $\mathrm{Au}$ element existed on the surface of Ag TNPs, suggesting formation of $\mathrm{Au}-\mathrm{Ag}$ alloy. This result was consistent with the previous report. ${ }^{34}$ Considering the catalytic ability of $\mathrm{Au}$ NPs and the alloy formation, $100 \mu \mathrm{L}$ of Au NPs aqueous solution was chosen in the next experimental.

\subsection{Colorimetric reactions for detection of glucose}

The reaction mechanism is illustrated in Fig. 2A. Small Au NPs catalyze the oxidation of glucose in the presence of oxygen to produce gluconic acid and $\mathrm{H}_{2} \mathrm{O}_{2}$, which etches $\mathrm{Ag}$ TNPs to result in the color change. It has been known that the localized surface plasmon resonance (LSPR) band of Ag TNPs is highly dependent on the tip sharpness and aspect ratio of nanoplates. ${ }^{35,36}$ Therefore, the etching of the Ag TNPs can lead to a blue shift of the inplane LSPR peak ( $\sim 630 \mathrm{~nm})$ and a decrease in the absorbance (Fig. 2B). The in-plane quadrupole LSPR band $(\sim 450 \mathrm{~nm})$ of $\mathrm{Ag}$ TNPs has gradually disappeared. The TEM images (Fig. 2C and D) confirm that the $\mathrm{Ag}$ TNPs change from triangle to round and further decrease the size of particles. Some of the two shapes segregated was observed in Fig. 2D. This may be related to TEM sample preparation and the region of recorded.

\subsection{Effect of Au NP stabilizers on the catalytic ability}

It was reported that citric acid adsorption does not inhibit the catalytic reactivity of $\mathrm{Au} \mathrm{NPs}^{37,38}$ However, organic 

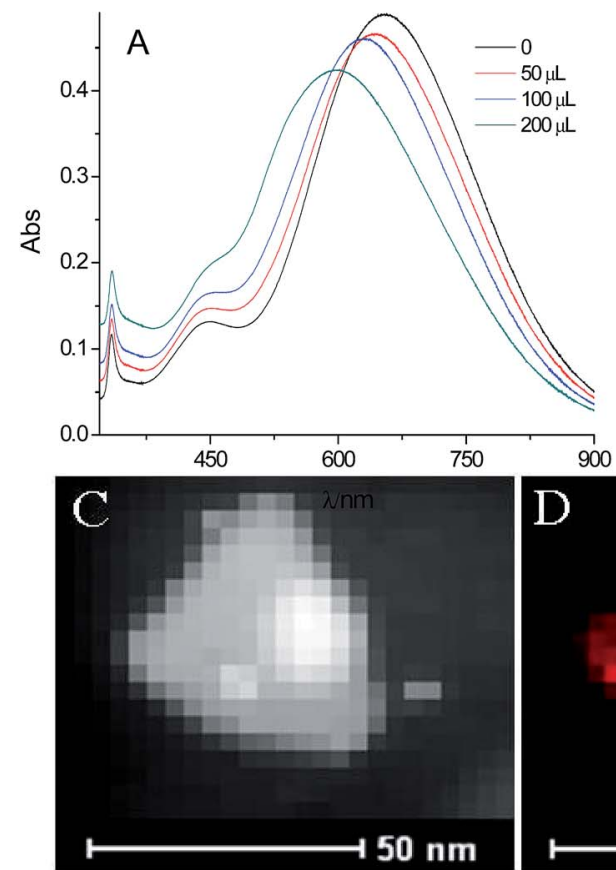
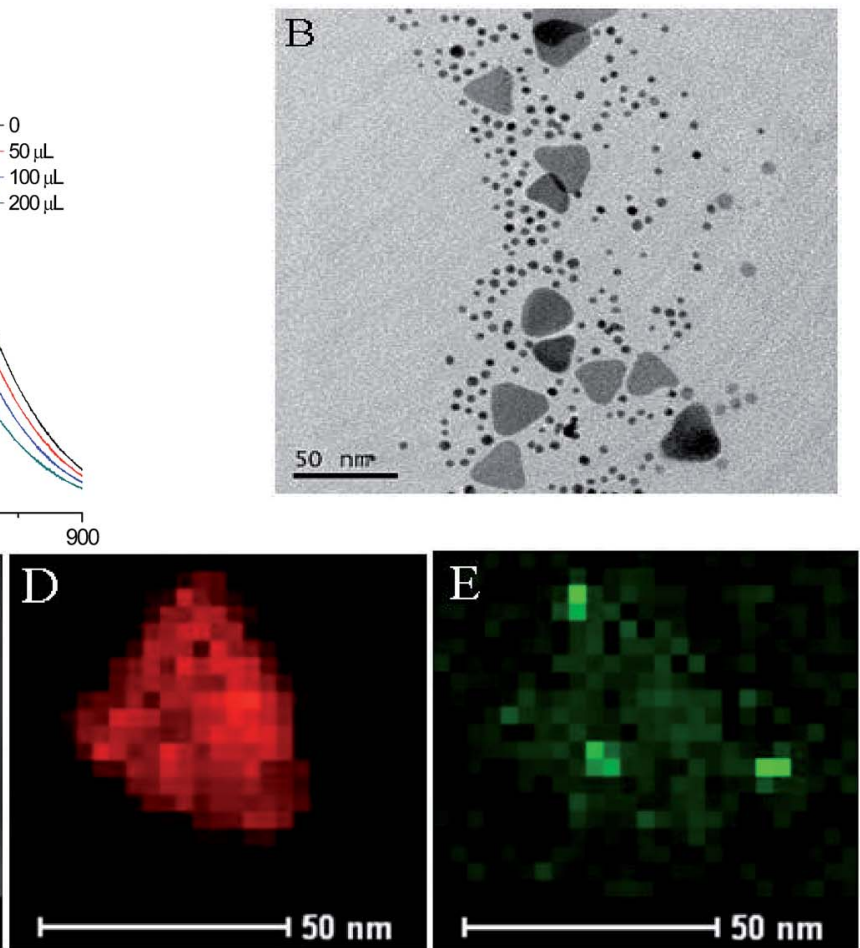

Fig. 1 The UV-vis absorption spectrum of the Ag TNPs-Au NPs with different volume (a), the TEM image of Ag TNPs solution mixed with $100 \mathrm{uL}$ Au NPs (b), the STEM HAADF image of Ag TNPs-Au NPs (c), the EDX elemental mapping images of Ag-K (d), Au-M (e).

macromolecules, such as polyvinyl alcohol (PVA), polyethylene glycol (PEG), and protein et al., inhibit the reaction..$^{20,38}$ In our previous report, ${ }^{29}$ we found that Cys assembled on the surface of
Au NPs not only improved the selectivity in glucose detection but also maintain their catalytic reactivity. Fig. 3A shows the effect of Cys concentration on the catalytic ability of the Au NPs
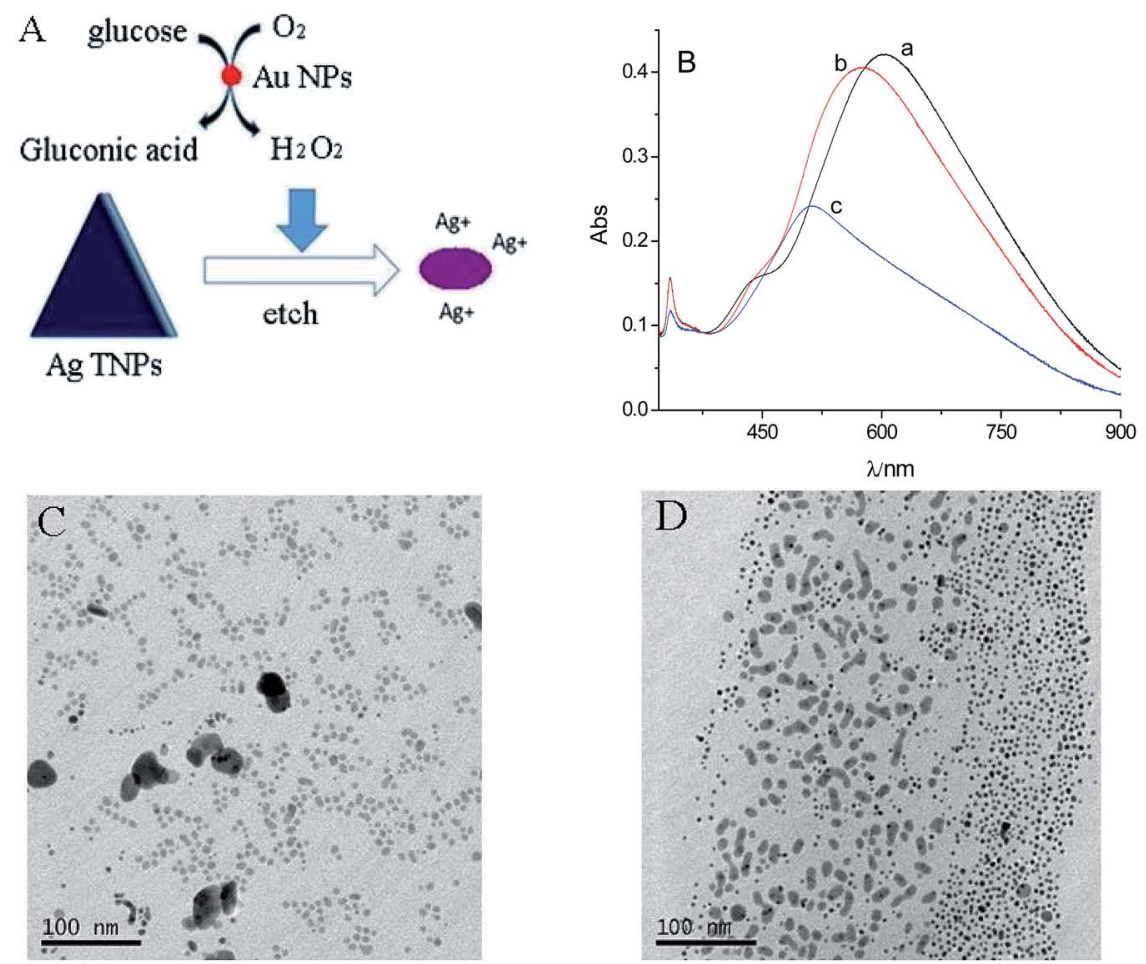

Fig. 2 Schematic illustration of the reactions for colorimetric detection of glucose (A). UV-vis absorption spectra before (curve a) and after addition of 10 (curve b) and $80 \mu \mathrm{M}$ (curve c) glucose (B). TEM images of metal nanomaterials after addition of 10 (C) and $80 \mu \mathrm{M}$ (D) glucose. 

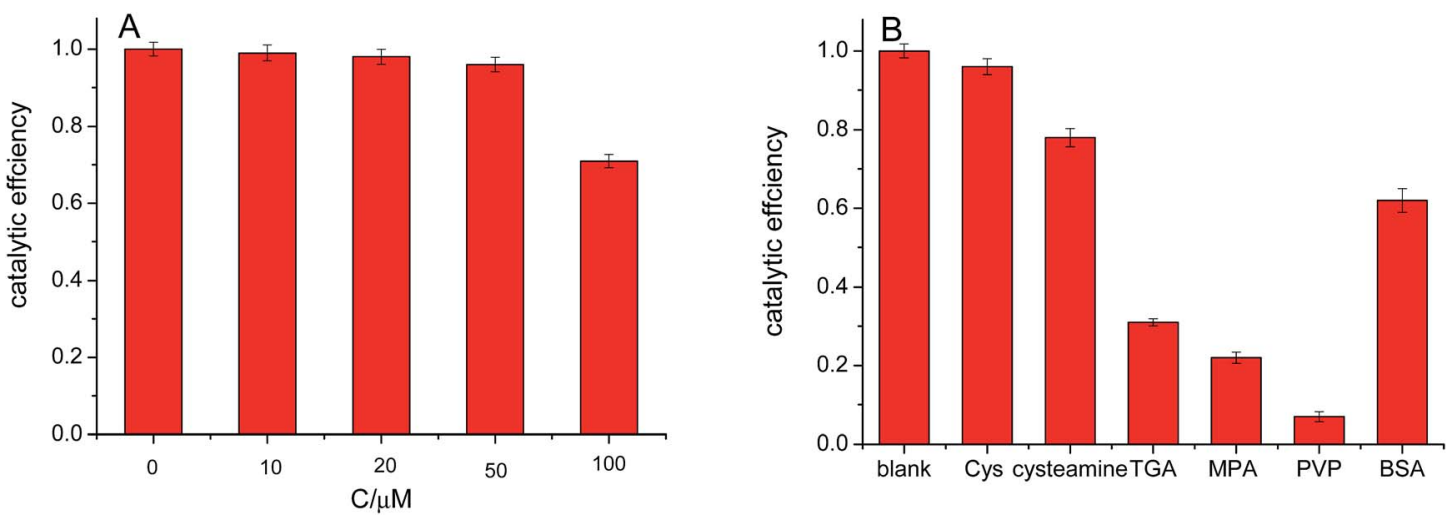

Fig. 3 Effect of Cys concentration (A) and $50 \mu \mathrm{M}$ various stabilizers except of $50 \mu \mathrm{gL}^{-1} \mathrm{BSA}$ (B) on the catalytic activity of Au NPs in the presence of $10 \mu \mathrm{M}$ glucose. Each error bar represents the standard deviation of three measurements.

for oxidation of glucose. It was found that the catalytic ability of $\mathrm{Au}$ NPs was almost not change as Cys concentration was not over $50 \mu \mathrm{M}$. However, the catalytic efficiency decreased to 0.71 when Cys concentration was $0.1 \mathrm{mM}$. This decrease may be attributed to aggregation of Au NPs in the presence of high Cys concentration. It was confirmed from the UV-vis absorption spectra of Au NPs after addition of different Cys concentration (Fig. S3 $\dagger$ ). As the Cys concentration was over $50 \mathrm{mM}$, the LSPR band of Au NPs became broad and red-shift in peak wavelength, indicating the aggregation of Au NPs. ${ }^{39,40}$ Moreover, we compared the catalytic ability of Au NPs modified with different stabilizers. As can be seen in Fig. 3B, Cys shows the least effect in the catalytic reaction.

\subsection{Optimization of experimental conditions}

In order to achieve the optimum conditions for glucose detection, we studied the influence of some important factors, including the reaction time and temperature. Fig. $4 \mathrm{~A}$ shows that the blue-shift of the LSPR peak increased as the reaction time increased (the raw spectroscopy data are provided in Fig. S4†). Moreover, the catalytic reaction rate was rapid at high incubation temperatures. The time reached maximum shift of peak wavelength decrease from $50 \mathrm{~min}$ at $25^{\circ} \mathrm{C}$ to $30 \mathrm{~min}$ at $35^{\circ} \mathrm{C}$.
The blue-shift wavelength decreased slightly when the incubation time was over $60 \mathrm{~min}$ at $35^{\circ} \mathrm{C}$, which may be attributed to the escape of $\mathrm{H}_{2} \mathrm{O}_{2}$ at high temperature. Therefore, $35{ }^{\circ} \mathrm{C}$ and 30-40 min were chosen in the next experiments.

The effect of the etching temperature and time on the wavelength shift was illustrated in Fig. 4B (spectra in Fig. S5†). The blue-shift of the peak increased with the increasing time and temperature. The plateau of the peak blue-shift reached in $40 \mathrm{~min}$ at $25^{\circ} \mathrm{C}$ but $30 \mathrm{~min}$ at $35^{\circ} \mathrm{C}$. Thus, $35^{\circ} \mathrm{C}$ and $30 \mathrm{~min}$ was taken as the etching conditions.

\subsection{Analytical performance}

To evaluate the analytical performance of the sensing method for detection of glucose under the optimized conditions, the UV-vis spectra in the presence of different concentration of glucose were recorded. With the increasing of the concentration of glucose, the main LSPR peak of Ag TNPs was gradually blueshift in wavelength and decreased in absorbance. The $\Delta \lambda$ (difference of main peak between control solution and after addition of glucose) showed a linear relationship with glucose concentrations with the range from $0.5 \mu \mathrm{M}$ to $20 \mu \mathrm{M}(\Delta \lambda=2.966$ $\left.\times C(\mu \mathrm{M})+0.425, R^{2}=0.999\right)$ with the detection limit of $0.3 \mu \mathrm{M}$ $(3 \sigma / S)$ (Fig. 5B). In addition, Fig. 5C shows that the calibration
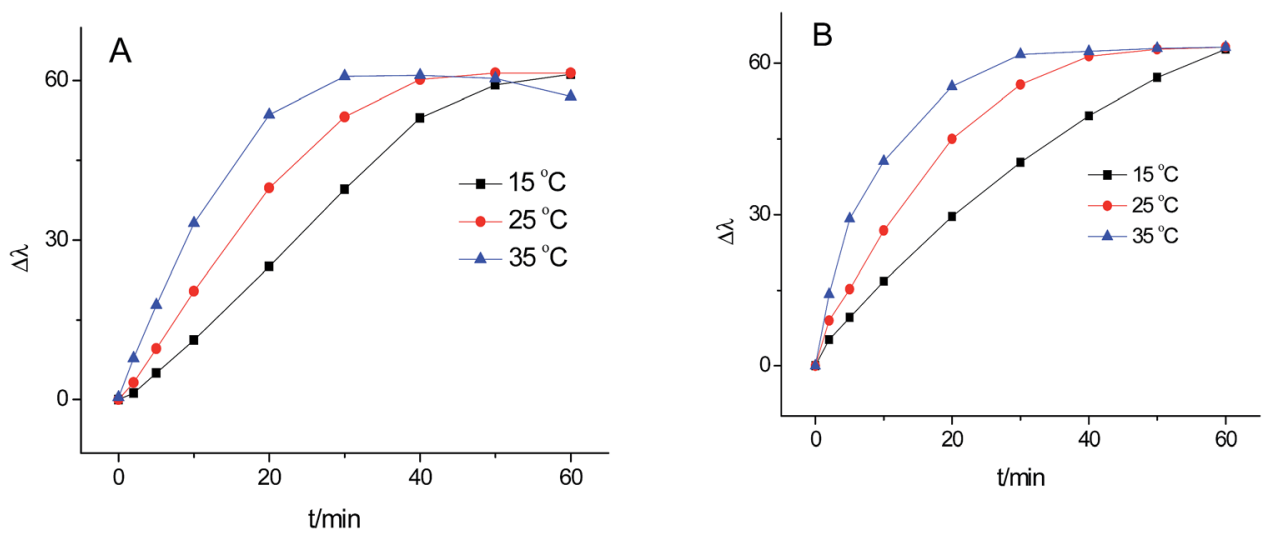

Fig. 4 Effect of temperature and time on catalytic oxidation of glucose (A), and effect of temperature and time on the etching of Ag TNPs (B). 

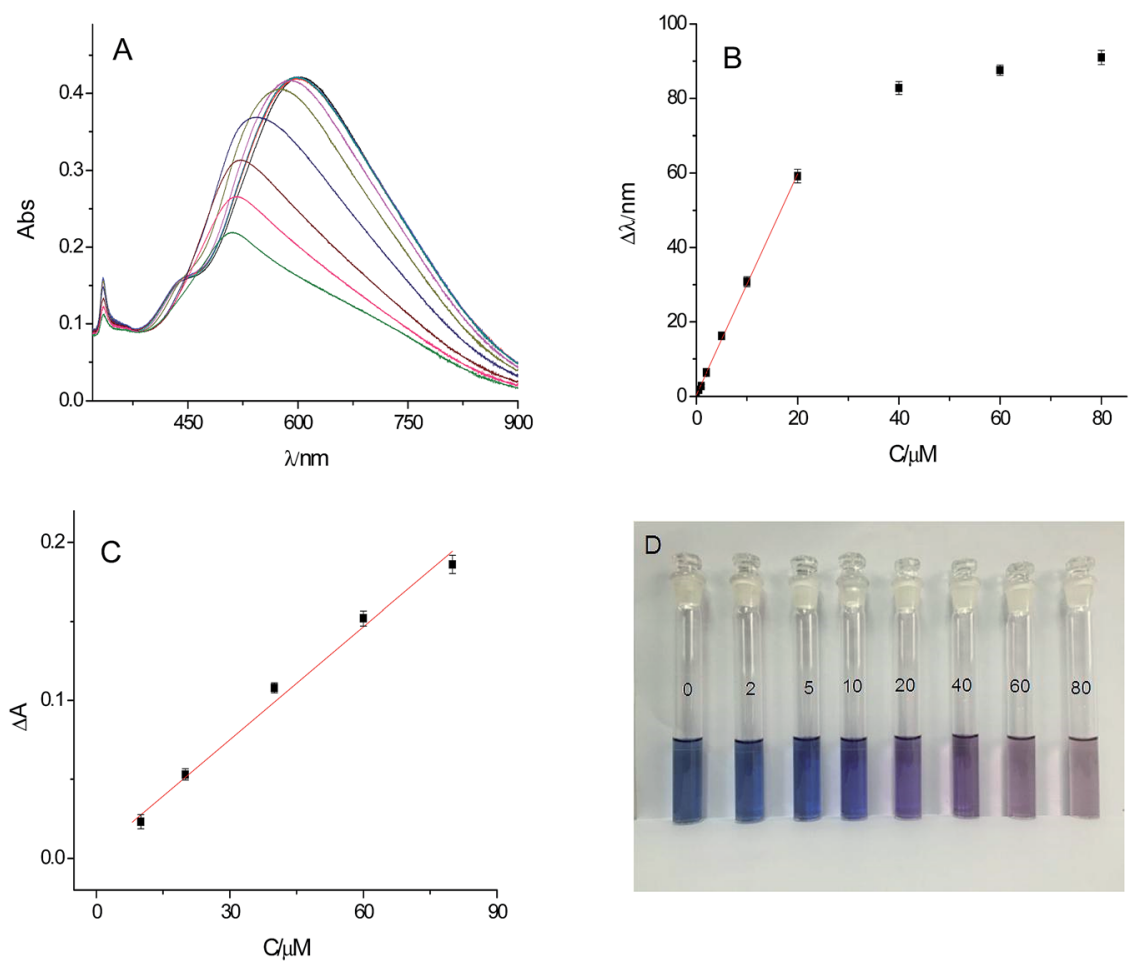

Fig. 5 (A) UV-vis absorption spectra of the system in the presence of glucose at various concentration (from top to bottom: $0,0.5,1,2,5,10,20$, $40,60,80 \mu \mathrm{M})$. (B) Linear calibration curves between the blue-shift of peak wavelength and (C) the absorbance at peak in the glucose concentration range of $0-80 \mu \mathrm{M}$. (D) Photograph of the system after addition of different glucose concentration. Each error bar represents the standard deviation of three measurements.

curve of the peak absorbance was obtained in the range of 10-80 $\mu \mathrm{M}\left(\Delta A=0.00239 \times C(\mu \mathrm{M})+0.00344, R^{2}=0.990\right)$. The higher sensitivity of detection was obtained in measurement of peak wavelength shift. Moreover, as exhibited in Fig. 5D, the color of solution was also marked changes from dark blue to purple and light pink with increasing concentration of glucose. Thus, the colorimetric method presents the potential for detection of blood glucose with the naked eye. Compared with some metal nanomaterials based methods (Table 1), this proposed colorimetric method is high sensitive.

\subsection{Selectivity and interferences}

Selectivity is a very important factor in practical sensing. We first examine some sugars, such as glucose, sucrose, fructose, lactose, and maltose. The response of lactose and maltose was similar to that of glucose, but sucrose and fructose showed no marketable change (Fig. 6A). This suggested that the Au NPs (a mimic GOD enzyme) is an oxidase with a broader substrate range than GOD enzyme.

Under the optimum experimental conditions, the possible interferences of inorganic ions and organic molecules for the detection of glucose $(10 \mu \mathrm{M})$ were examined. The same concentration of $\mathrm{Na}^{+}, \mathrm{K}^{+}, \mathrm{Zn}^{2+}, \mathrm{Ca}^{2+}, \mathrm{Pb}^{2+}$, glutamic acid (Glu), aspartic acid (Asp), arginine (Arg), glycine (Gly), tryptophan (Trp), AA, UA, PA, DA, and BSA were not interfering with the detection of glucose (Fig. 6). In the absence of Cys, proteins may be adsorbed on the surface of Au NPs, ${ }^{46}$ inhibiting the catalytic reaction of Au NPs (Fig. 3B). The Cys assembled on the surface

Table 1 Comparison of the analytical performance of metal nanomaterials based methods for spectral detection of glucose

\begin{tabular}{|c|c|c|c|c|}
\hline Colorimetry & $\mathrm{Cu}-\mathrm{Ag} / \mathrm{rGO}$ & $0.001-0.03$ & 3.82 & 41 \\
\hline Chemiluminescence & Dendritic Au-Ag & $0.001-1$ & 0.4 & 42 \\
\hline Colorimetry & GOx/AgNPs & $0.278-4.44$ & 127 & 26 \\
\hline Colorimetry & GOx/AgNPs-GQDs & $0.0005-0.4$ & 0.17 & 27 \\
\hline Colorimetry & GOx/Au@AgNPs & $0.0005-0.4$ & 0.24 & 43 \\
\hline Colorimetry & AuNPs/AgNPs & $0.005-0.07$ & 3 & 29 \\
\hline Colorimetry & AuNPs/AgTNPs & $0.0005-0.02$ & 0.3 & This work \\
\hline
\end{tabular}



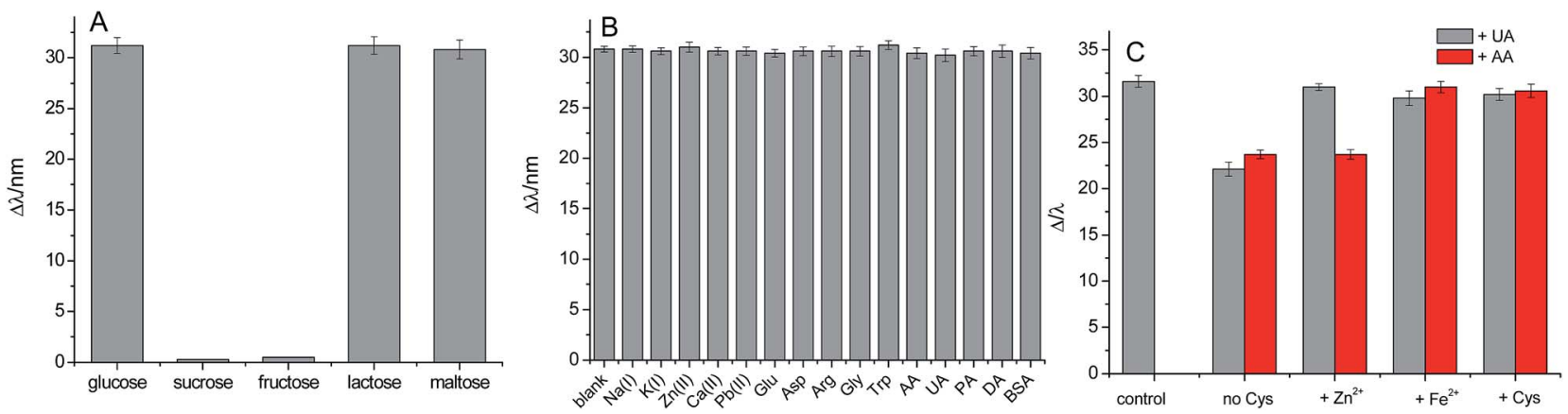

Fig. 6 LSPR peak shift $(\Delta \lambda)$ of the Au NPs-Ag TNPs system in various to test selectivity (A). LSPR peak shift $(\Delta \lambda)$ of the Au NPs-Ag TNPs system incubating with $10 \mu \mathrm{M}$ of glucose in the presence of same concentration of various potential interfering substances except for $50 \mu \mathrm{mL} \mathrm{mL}^{-1} \mathrm{BSA}$ and $0.5 \mu \mathrm{M} \cup A(B)$. LSPR peak shift $(\Delta \lambda)$ of the Au NPs-Ag TNPs system at different condition (10 $\mu$ M of glucose and addition of $1 \mu M$ of UA or 10 $\mu M$ of $A A)(C)$. The error bars represent the relative standard.

Table 2 Detection of glucose in human blood $(N=3)$

\begin{tabular}{lllcccc}
\hline Sample & Detected $/ \mu \mathrm{M}$ & Added $/ \mu \mathrm{M}$ & Found $/ \mu \mathrm{M}$ & Recovery $/ \%$ & Our method/mM & Hospital method/mM \\
\hline 1 & $5.24 \pm 0.17$ & 5.00 & 10.45 & 104.2 & 5.24 & 5.24 \\
2 & $4.18 \pm 0.13$ & 5.00 & 8.92 & 94.8 & 4.18 & 4.08 \\
3 & $5.12 \pm 0.12$ & 5.00 & 10.00 & 97.6 & 5.12 & 5.00
\end{tabular}

of Au NPs can inhibit the adsorption of protein. In addition, the detection of glucose was interfered seriously with UA and AA in the absence of Cys. This was attributed to the adsorption of UA and AA on the surface of $\mathrm{Ag}$ TNPs which resulted in inhibition of them from etching. ${ }^{8}$ It was confirmed by the fact that the interference of UA could be avoided after addition of $\mathrm{Zn}^{2+}$ or $\mathrm{Fe}^{2+}$ in the system. In this work we demonstrated that the interferences of UA and AA can be also eliminated in the presence of Cys, which assembled on the surface of Ag TNPs.

\subsection{Sample analysis}

Herein, we tested the concentration of glucose in human serum samples, obtained from Soochow Hospital. After diluting the serum 1000 times, the standard addition method was used to detect the actual sample. Table 2 shows the analytical results obtained from this method. The good recoveries, between $94.8 \%$ and $104.2 \%$, indicated that this glucose sensing was effectively applied in the detection blood glucose.

\section{Conclusions}

We developed a sensitive method for the detection of glucose in human serums using integration of Au NPs and Ag TNPs. The small $\mathrm{Au}$ NPs catalytically oxidized glucose in presence of oxygen to produce $\mathrm{H}_{2} \mathrm{O}_{2}$, which induced etching of $\mathrm{Ag}$ TNPs to result in color change. The plasmonic peak of Ag TNPs was proportionally blue-shifted with glucose concentration in the range $0.5-20 \mu \mathrm{M}$. Furthermore, the color of the solution was observable from blue to light pink in the range $2-80 \mu \mathrm{M}$. The proposed method was simple, sensitive, cost-effective and avoid any enzymes and organic chromogenic agents. The method enriches the application of nanotechnology and provides an insight into mimic enzyme and biosensing.

\section{Acknowledgements}

This work was financially supported by the National Natural Science Foundation of China (No. 21475092) and the Priority Academic Program Development of Jiangsu Higher Education Institutions.

\section{Notes and references}

1 S. P. Nichols, A. Koh, W. L. Storm, J. H. Shin and M. H. Schoenfisch, Chem. Rev., 2013, 113, 2528-2549.

2 C. Chen, Q. Xie, D. Yang, H. Xiao, Y. Fu, Y. Tan and S. Yao, RSC Adv., 2013, 3, 4473.

3 A. Senthamizhan, B. Balusamy and T. Uyar, Anal. Bioanal. Chem., 2016, 408, 1285-1306.

4 Q. Wu, L. Wang, H. Yu, J. Wang and Z. Chen, Chem. Rev., 2011, 111, 7855-7875.

5 M. I. Maiorino, G. Bellastella, M. Caputo, F. Castaldo, M. R. Improta, D. Giugliano and K. Esposito, J. Diabetes. Complications, 2016, 30, 1519-1524.

6 X. Zhang, X. Bi, W. Di and W. Qin, Sens. Actuators, B, 2016, 231, 714-722.

7 J. Mu, Y. He and Y. Wang, Talanta, 2016, 148, 22-28.

8 Y. Xia, J. Ye, K. Tan, J. Wang and G. Yang, Anal. Chem., 2013, 85, 6241-6247.

9 S. Dong, Q. Yang, L. Peng, Y. Fang and T. Huang, Sens. Actuators, B, 2016, 232, 375-382. 
10 Q. Shi, G. Diao and S. Mu, Electrochim. Acta, 2014, 133, 335346.

11 J. Song, L. Xu, R. Xing, W. Qin, Q. Dai and H. Song, Sens. Actuators, B, 2013, 182, 675-681.

12 H. Li, C. Y. Guo and C. L. Xu, Biosens. Bioelectron., 2015, 63, 339-346.

13 S. Zhou, X. Min, H. Dou, K. Sun, C. Y. Chen, C. T. Chen, Z. Zhang, Y. Jin and Z. Shen, Chem. Commun., 2013, 49, 9473-9475.

14 J. C. Pickup, F. Hussain, N. D. Evans, O. J. Rolinski and D. J. Birch, Biosens. Bioelectron., 2005, 20, 2555-2565.

15 M. J. Chaichi and S. O. Alijanpour, J. Photochem. Photobiol., $B, 2014,140,41-48$.

16 M. Hao, N. Liu and Z. Ma, Analyst, 2013, 138, 4393-4397.

17 V. K. Gupta, N. Atar, M. L. Yola, M. Eryilmaz, H. Torul, U. Tamer, I. H. Boyaci and Z. Ustundag, J. Colloid Interface Sci., 2013, 406, 231-237.

18 M. S. Steiner, A. Duerkop and O. S. Wolfbeis, Chem. Soc. Rev., 2011, 40, 4805-4839.

19 J. M. Harris, C. Reyes and G. P. Lopez, J. Diabetes Sci. Technol., 2013, 7, 1030-1038.

20 M. Comotti, C. Della Pina, R. Matarrese and M. Rossi, Angew. Chem., 2004, 43, 5812-5815.

21 P. Beltrame, M. Comotti, C. Della Pina and M. Rossi, Appl. Catal., A, 2006, 297, 1-7.

22 D. Zeng, W. Luo, J. Li, H. Liu, H. Ma, Q. Huang and C. Fan, Analyst, 2012, 137, 4435-4439.

23 T. K. Sau and A. L. Rogach, Adv. Mater., 2010, 22, 1781-1804.

24 L. M. Liz-Marzán, Langmuir, 2006, 22, 32-41.

25 Q. Zhang, C. M. Cobley, J. Zeng, L.-P. Wen, J. Chen and Y. Xia, J. Phys. Chem. C, 2010, 114, 6396-6400.

26 J. Tashkhourian, M. R. Hormozi-Nezhad, J. Khodaveisi and R. Dashti, Sens. Actuators, B, 2011, 158, 185-189.

27 S. Chen, X. Hai, X. W. Chen and J. H. Wang, Anal. Chem., 2014, 86, 6689-6694.
28 H. He, X. Xu, H. Wu and Y. Jin, Adv. Mater., 2012, 24, 17361740.

29 Y. Gao, Y. Wu and J. Di, Spectrochim. Acta, Part A, 2016, 173, 207-212.

30 Z. Chen, C. Zhang, Q. Wu, K. Li and L. Tan, Sens. Actuators, B, 2015, 220, 314-317.

31 X. Yang, Y. Yu and Z. Gao, ACS Nano, 2014, 8, 4902-4907.

32 Q. Zhang, N. Li, J. Goebl, Z. Lu and Y. Yin, J. Am. Chem. Soc., 2011, 133, 18931-18939.

33 R. Jin, Y. Cao, C. A. Mirkin, K. L. Kelly, G. C. Schatz and J. G. Zheng, Science, 2001, 294, 1901-1903.

34 T. Shibata, B. A. Bunker, Z. Zhang, D. Meisel and J. D. Gezelter, J. Am. Chem. Soc., 2002, 124, 11989-11996.

35 B. Tang, S. Xu, J. An, B. Zhao and W. Xu, J. Phys. Chem. C, 2009, 113, 7025-7030.

36 X. Y. Hou, S. Chen, J. Tang and Y. F. Long, Spectrochim. Acta, Part A, 2014, 125, 285-289.

37 W. Luo, C. Zhu, S. Su, D. Li, Y. He, Q. Huang and C. Fan, ACS Nano, 2010, 4, 7451-7458.

38 N. J. Lang, B. Liu and J. Liu, J. Colloid Interface Sci., 2014, 428, 78-83.

39 A. Mocanu, I. Cernica, G. Tomoaia, L.-D. Bobos, O. Horovitz and M. Tomoaia-Cotisel, Colloids Surf., A, 2009, 338, 93-101.

40 P. Řezanka, H. Řezanková, P. Matějka and V. Král, Colloids Surf., A, 2010, 364, 94-98.

41 G. Darabdhara, B. Sharma, M. R. Das, R. Boukherroub and S. Szunerits, Sens. Actuators, B, 2017, 238, 842-851.

42 H. Yu and Y. He, Sens. Actuators, B, 2015, 209, 877-882.

43 X. Zhang, M. Wei, B. Lv, Y. Liu, X. Liu and W. Wei, RSC Adv., 2016, 6, 35001-35007.

44 A. K. Dutta, S. Das, S. Samanta, P. K. Samanta, B. Adhikary and P. Biswas, Talanta, 2013, 107, 361-367.

45 J. Li, Y. Li, S. A. Shahzad, J. Chen, Y. Chen, Y. Wang, M. Yang and C. Yu, Chem. Commun., 2015, 51, 6354-6356.

46 M. S. Bakshi, H. Kaur, P. Khullar, T. S. Banipal, G. Kaur and N. Singh, J. Phys. Chem. C, 2011, 115, 2982-2992. 